\title{
How are parental practices and attitudes towards corporal punishment related to child academic, developmental, or psychological-emotional dysfunctioning?
}

Roberto Grujicic

Institute of Mental Health

Oliver Toskovic

Laboratory for Experimental Psychology, Faculty of Philosophy, University of Belgrade

Ljiljana Lazarevic

Institute of Psychology, Faculty of Philosophy, University of Belgrade

Vanja Mandic Maravic

Institute of Mental Health

Marija Mitkovic Voncina

Institute of Mental Health

Ana Radanovic

Institute for Educational Research, University of Belgrade

Jelena Radosavljev Kircanski

Institute of Mental Health

Marina Videnovic

Institute of Psychology, Faculty of Philosophy, University of Belgrade

\section{Tatjana Pekmezovic}

Faculty of Medicine, University of Belgrade

Milica Pejovic Milovancevic ( $\nabla$ milica.pejovic@imh.org.rs )

Institute of Mental Health

\section{Research Article}

Keywords:

Posted Date: January 27th, 2022

DOI: https://doi.org/10.21203/rs.3.rs-1233140/v1

License: (a) This work is licensed under a Creative Commons Attribution 4.0 International License. Read Full License 
Page $2 / 21$ 


\section{Abstract}

Corporal punishment (CP) is a widely spread disciplining technique among parents and caregivers globally. The aim of our paper was to explore the relationship between the parental attitudes towards $\mathrm{CP}$, expected outcomes of $\mathrm{CP}$, and parenting practices on one hand, with the reported dysfunctions of their children. In addition, we aimed to explore the relationship between the use of $\mathrm{CP}$ and the reported academic, developmental and psychological-emotional dysfunctions of their children. The present study involved a nationally representative sample of 1186 parents in Serbia, who had at least one child aged 0 to 18 years in the moment of interviewing. The parents filled out a series of interviews on their attitudes towards $\mathrm{CP}$, expectations of $\mathrm{CP}$ outcomes and their parental practices. Our findings indicate that parents that report having a child with dysfunctions have positive attitudes towards CP and expect positive outcomes of CP. These parents also report using more CP as a disciplining method, as well as other harsh disciplining techniques. We also identified significant predictors of reported child dysfunctions. When these measured effects combine, this puts the children with health-related and school-related issues at a significant risk of further maltreatment and abuse.

\section{Introduction}

Corporal punishment (CP), or commonly referred to as 'disciplinary spanking', is usually defined as "the use of physical force with the intention of causing a child to experience pain, but not injury, for the purpose of correcting or controlling the child's behavior" ${ }^{1}$. It includes behaviors such as hitting, punching, shaking, or throwing objects at a child. Historically, the use of CP was universally present in every culture, traditionally accepted and shaped over time by different personal, religious, social and cultural values. However, there was a sharp change in paradigm in the last couple of decades when CP was labeled as a form of abuse against children ${ }^{2}$. In spite of the preventive efforts worldwide ${ }^{3}$, the epidemiological studies surprisingly show that many parents (up to $80 \%$ of parents worldwide) still use CP to discipline their children ${ }^{4,5}$. This has made the use of $\mathrm{CP}$ in child-rearing the most controversial topic in the parentchild relations and led to a strong research interest and hyperproduction of studies ${ }^{6}$. The majority of these studies are focused on the consequences of the use of CP on children, without sufficient evidence on the contributing factors and causality of such behavior ${ }^{7}$.

The existing literature indicates that children with disabilities are more often subjected to harsh discipline and $\mathrm{CP}$ in comparison to children without disabilities ${ }^{8,9}$. More specifically, this has been a case when parenting a child that has a problem in attention ${ }^{10}$, antisocial behavior ${ }^{11}$ and physical disabilities ${ }^{12}$. The findings also indicate that children with certain disabilities are more subjected to CP than others. For example, children with problems in communication (hearing problems or speech problems) are more often subjected to $\mathrm{CP}$ than others due to the inability of proper parent-child communication ${ }^{9,13}$. However, most of these studies focus on a child's dysfunction in a single domain, and do not include dysfunctions in other domains that can be common in children, such as academic functioning and psychologicalemotional functioning. 
Previous research shows that parenting children with dysfunctions in domains such as mental health can be a significant source of burden and distress for the parent and the whole family ${ }^{14,15}$. Consequently, parental distress can be a significant risk factor for the use of $\mathrm{CP}$, especially when combined with other factors such as their previous experience of physical punishment, favorable attitudes towards physical punishment, and lack of sufficient support ${ }^{16}$.

The existing body of research on CP shows no evidence of a long-term improvement in child behavior or any aspect of development when physical force is used ${ }^{2,6}$. Regardless of this unequivocal evidence, many parents still believe in the 'benefits' of $\mathrm{CP}$ and use it as part of their disciplining practices ${ }^{5,17}$. The parental attitudes and norms towards $\mathrm{CP}$ can range greatly, from a belief that $\mathrm{CP}$ is acceptable and good for the child to the belief that any type of physical punishment is a form of abuse ${ }^{17,18}$. The parental attitudes and norms can be associated with a number of factors such as their social surroundings, country of origin, cultural background, and individual factors related to parents and families (e.g. education, social support, socioeconomic status, health, etc.) ${ }^{7,19-21}$. Back in 1991, Korbin was one of the first authors that highlighted the fact that cultural norms and parental attitudes shape parental opinions on what is child abuse and what is not ${ }^{22}$. The research that followed this theory proved that parental attitudes towards the use of CP significantly shape their parental practices and the frequency of $\mathrm{CP} 21,23$. In addition, it has been shown that parental expectations of CP effects are an important factor that influences the use of CP. In other words, the parents who expect positive outcomes out of CP, tend to use $\mathrm{CP}$ more frequently ${ }^{18,23}$. To our knowledge, there is no data in the current literature on possible mediating roles of parental attitudes and expected outcomes of $\mathrm{CP}$ when parenting a child with a certain dysfunction.

The primary aim of this research was to explore the relationship between the parental attitudes towards $\mathrm{CP}$, expected outcomes of $\mathrm{CP}$, and parenting practices on one hand, with the reported dysfunctions of their children. In addition, we aimed to explore the relationship between the use of $\mathrm{CP}$ and the reported academic, developmental and psychological-emotional dysfunctions of their children.

\section{Materials And Methods}

\section{Participants}

The study involved a nationally representative sample of 1186 parents in Serbia, who had at least one child aged 0 to 18 years in the moment of interviewing.

The sample size was determined based on several parameters: the instruments used in the study (power of tests and significance levels), expected response rate and size effects. The sampling method was divided in three stages. The first stage was stratified sampling, when the Republic of Serbia was divided into four main regions. The next stage was cluster sampling, when the clusters of 70 municipalities were selected randomly. These clusters were proportional to the regions size and settlement type (urban/rural). 
The final stage was the selection of participants via the random-walk sampling method in each of selected areas.

The socio-demographic data of the respondents in our sample are presented in Table 1. The majority of our sample were mothers $(\mathrm{N}=755 ; 63.8 \%)$. About half of the respondents finished secondary school, whereas $44.3 \%$ had higher levels of education. The mean age of our participants was $38.08(S D=8.06)$.

Table 1

The sociodemographic data of parents.

\begin{tabular}{|c|c|c|}
\hline Variable & $\mathbf{N}(\%)$ & Mean \pm SD \\
\hline \multicolumn{3}{|l|}{ Gender } \\
\hline Male & $428(36.2)$ & \\
\hline Female & $755(63.8)$ & \\
\hline Age (years) & & $38.08(8.06)$ \\
\hline \multicolumn{3}{|l|}{ Area type } \\
\hline Urban & $506(43.5)$ & \\
\hline Rural & $656(56.5)$ & \\
\hline \multicolumn{3}{|l|}{ Level of education } \\
\hline Elementary school & $63(5.3)$ & \\
\hline Secondary school & $596(50.4)$ & \\
\hline Two year college & $159(13.4)$ & \\
\hline University & $266(22.5)$ & \\
\hline Specialization, master studies, doctorate & $99(8.4)$ & \\
\hline
\end{tabular}

\section{(Table 1 about here)}

\section{Data collection and data analysis}

The data collection process took place in the participants' homes, face-to-face. The questionnaires were delivered by previously trained interviewers through one of two methods: computer-assisted personal interviewing (CAPI) or through the paper-pencil method. Participants filled out the questionnaires by themselves and were free to ask questions or any kind of additional help from the interviewers. The data analysis encompassed the descriptive methods (frequencies, percentages, means, and standard deviations), testing differences between groups (Student's t-test) and multivariate analysis (linear regression). All analyses were conducted in SPSS software, version 20.

\section{Ethics}


This study has been approved by the Ethics Committee of the Institute of Mental Health and has been performed in accordance with the principles of good clinical practice (No1060/2089/1). The informed consent was obtained from all the participants prior to taking part in the research. The informed consent forms were kept separately from the questionnaires. Also, the questionnaires were filled out anonymously, thus the confidentiality and privacy of all participants were guaranteed.

\section{Instruments}

\section{General information questionnaire}

The general information questionnaire was designed specifically for this study with the aim of covering the most relevant socio-demographic information. The first part of the questionnaire was assessed the information on the parents (e.g. age, gender, education, employment). The second part assessed parental reports on different dysfunctions that their children are facing. We categorized the problems of children into three groups: (1) Developmental dysfunctions (vision problems, hearing problems, speech problems, intellectual disability, motoric problems, neurodevelopmental difficulties (e.g. autism), attention /hyperactivity problem, learning difficulties); (2) Psychological-emotional dysfunctions (aggressive behavior, suicide attempts, nonsuicidal self-injury); (3) Academic dysfunctions (i.e. problems related to school attendance and achievements; unsatisfactory achievement, adaptation problems, truanting). Respondents were asked questions like: "Do you have a child who has speech problems", "Did your child receive treatment for his/hers speech problems", or "Do you have a child who ever attempted suicide", etc.

\section{Conflict Tactics Scales: Parent-Child Version (CTSPC)}

The Parent-Child Conflict Tactics Scales (CTSPC) is an modified version of the Conflict Tactics Scale (CTS) developed by Straus et al ${ }^{24,25}$. The CTS scale was primarily designed to measure the presence of and degree of maltreatment among partners in a marital, cohabiting or dating relationship. The CTSPC scale was modified in a way to assess parent-child relationships. The final version of CTSPC questionnaire consists of 35 items that assess the presence and severity of various forms of parental practices. It is a parent self-report questionnaire that consists of six scales: Nonviolent Discipline; Psychological Aggression; Physical Assault; Supplemental Questions on Discipline in the Previous Week; Neglect; and Sexual Abuse. Each scale contains questions that are scored by the eight-point Likert type scale that ranges from "once in the past year" to "more than 20 times within the past year". Two responses that don't reflect presence of practices in the past year are "not in the past year but it happened before" and "this never happened". All responses that reflected the frequency of practices in the last year were further marked as "last year", while the response "not in the past year but it happened before" was marked as "lifetime". In addition to the overall physical punishment scale, there are three subscales associated with physical assault - the minor physical punishment scale (i.e. CP), the severe physical assault scale, and very severe (i.e. extreme) physical assault scale. The CTSPC was validated in 2018 by Cotter et al ${ }^{26}$ and the scale showed good internal consistency (Cronbach's $\mathrm{a}=0.88$ ).

\section{Attitudes toward Physical Punishment (ATPP)}


The ATPP is a self-report questionnaire that consists of 12 items that measure the parental attitudes and opinions regarding the use of physical punishment as a part of child-rearing. This version of the questionnaire was based on the Discipline Questionnaire (DQ) from the research lead by Graziano et al

27. The questions were answered on a 5- point Likert-type scale ranging from 1 (strongly disagree) to 5 (strongly agree). According to the previous research, the test showed good internal consistency (Cronbach's $a=0.84)$ and high test-retest reliability $(r=.76)^{27}$.

\section{Expected outcomes of using CP}

The expected outcomes of using CP are based on the scale Outcomes of Physical Punishment Scale developed by Durrant et al. in 2003 and modified by Taylor et al. ${ }^{18}$. The final scale consists of 14 items, equally distributed in two subscales. The first subscale measured 'positive outcomes', while the second scale measured 'negative outcomes' of corporal punishment. The positive outcomes included 'positive' effects on a child such as correction in short- and long-term behaviors, better family relations, learning self-control. In contrast, negative outcomes refer to the negative effects on a child's wellbeing and functioning, such as injuries, abuse, aggressive behavior, physical and mental health consequences. Participants rated each item on a 5-point Likert scale ranging from $1=$ never to $5=$ always. For each subscale, an average score was calculated for each set of items. According to previous research, the two subscales showed good internal consistency; Cronbach's a for expected positive and negative outcomes were 0.88 and 0.89 respectively.

\section{Results}

The descriptives on the reported dysfunctions of children are presented in Table 2. In order to analyze the parental attitudes, norms and practices in accordance to the reported child dysfunctions, we first divided the sample into two major groups; the first group was comprised of parents who reported having a child with dysfunctions in any area (e.g. development, psychological-emotional, academic) while the second group was comprised of parents who reported having a child without any dysfunctions. In order to obtain more specific results, we further divided the first group into three subgroups according to the reported problems the children were facing: (1) Developmental dysfunctions; (2) Psychological-emotional dysfunctions; (3) Academic dysfunctions (i.e. dysfunctions related to school attendance and school achievements). 
Table 2

The problems that children are facing according to the parental report.

\begin{tabular}{|l|l|}
\hline Variable & N (\%) \\
\hline Developmental dysfunctions & $237(20.0)$ \\
\hline Vision problems & $145(12.2)$ \\
\hline Hearing problems & $16(1.3)$ \\
\hline Speech problems & $64(5.4)$ \\
\hline Intellectual disability & $4(0.3)$ \\
\hline Motoric problems & $18(1.5)$ \\
\hline Neurodevelopmental difficulties (e.g. autism spectrum disorders) & $7(0.6)$ \\
\hline Attention /hyperactivity problem & $6(0.5)$ \\
\hline Learning difficulties & $10(0.8)$ \\
\hline Psychological-emotional dysfunctions & $45(3.9)$ \\
\hline Suicide attempt & $5(0.4)$ \\
\hline NSSI & $17(1.5)$ \\
\hline Violent towards others & $22(1.9)$ \\
\hline Academic dysfunctions (i.e. problems related to school attendance and achievements) & $323(27.2)$ \\
\hline Unsatisfactory achievement & $120(10.1)$ \\
\hline Bad grades & $83(7.0)$ \\
\hline Adaptation problems & $199(16.8)$ \\
\hline Truanting & $61(5.1)$ \\
\hline
\end{tabular}

The developmental dysfunctions were reported in every fifth child. The most common reported developmental dysfunctions were the vision problems, followed by speech problems (Table 2). Out of all parents, $18 \%(\mathrm{~N}=213)$ reported having the child with one developmental dysfunction, $1.8 \%(\mathrm{~N}=21)$ reported two developmental dysfunctions, while 3 parents $(0.3 \%)$ had reported having a child with three developmental dysfunctions at the same time.

The psychological-emotional dysfunctions were reported in almost $4 \%$ of our sample. The parents mostly reported having a child who was aggressive, or was engaged in non-suicidal self-injury (NSSI). Having a child with a one psychological-emotional dysfunction was reported by $3 \%(\mathrm{~N}=41)$ of the parents, while conjoint psychological-emotional dysfunctions in children were reported by $0.3 \%$ of the parents $(\mathrm{N}=3)$. 
The most parents from our sample reported having a child with academic dysfunctions. The most common reported dysfunction was related to problems in adaptation to school. Having a child with one school dysfunction was detected in $18.7 \%$ of the sample ( $\mathrm{N}=222)$, two academic dysfunctions in $5.8 \%$ $(\mathrm{N}=69)$, while three conjoint academic dysfunctions were reported in $2.1 \%(\mathrm{~N}=25)$ children.

\section{Expected outcomes of CP}

The two groups of parents with and without the reported dysfunctions in children were compared in how much they expect positive and negative outcomes of CP. The t-test for independent samples showed a statistically significant difference between the two groups $(p<.001)$. The parents who had children with dysfunctions more often reported that they expected that the outcomes of CP were positive (e.g. improvement in child behavior, increase in respect towards a parent, learning correct behavior, etc). We, then, compared the expectations of $\mathrm{CP}$ in the participants with and without the reported dysfunction in children, for each of the three types of dysfunctions (Table 3). The groups of parents with each type of child dysfunction reported believing more in positive outcomes of CP (Table 3), whereas no differences were found when it comes to expectations of negative outcomes $(p>.05)$.

Table 3

Differences in expectations of positive outcomes of corporal punishment between parents with and without the reported child dysfunction

\begin{tabular}{|lllllll|}
\hline Groups & N & Mean & SD & t & df & P \\
\hline Any repored dysfunction & 477 & 2,1180 & 1,095 & $-3,516$ & 978,435 &, $000^{*}$ \\
\hline No reported dysfunctions & 703 & 1,8950 & 1,028 & & & \\
With academic dysfunctions & 322 & 2,1188 & 1,099 & $-2,658$ & 1178 &, 008 \\
\hline Without academic dysfunctions & 858 & 1,9349 & 1,043 & & & \\
\hline With developmental dysfunctions & 235 & 2,1903 & 1,073 & $-3,325$ & 1178 &, 000 \\
\hline Without developmental dysfunctions & 945 & 1,9341 & 1,052 & & & \\
\hline With psychological-emotional dysfunctions & 44 & 2,5817 & 1,346 & $-3,018$ & 45,020 &, 004 \\
\hline $\begin{array}{l}\text { Without psychological-emotional } \\
\text { dysfunctions }\end{array}$ & 1136 & 1,9620 & 1,042 & & & \\
\hline
\end{tabular}

\section{Attitudes toward CP among parents}

Then we examined the differences in attitudes towards CP between the groups of parents of children with or without any reported dysfunctions. The differences in attitudes towards CP are shown in Table 4. We found that the parents who reported having a child with dysfunctions have significantly more positive attitudes towards $\mathrm{CP}$ than the parents of children without reported dysfunctions. Additionally, we examined each group of parents according to the dysfunctions of their child (Table 4). When compared with parents of children without reported dysfunctions, we found a statistically significant difference in 
attitudes in parents with children with academic dysfunctions and psychological-emotional dysfunctions. There was no difference in the attitudes among parents with children with and without developmental dysfunctions.

Table 4

Positive attitudes of parents towards violent disciplining methods among the interviewed parents

\begin{tabular}{|lllllll|}
\hline Groups & N & Mean & SD & t & df & p \\
\hline Any repored dysfunctions & 478 & 1,9349 &, 833 & $-2,484$ & 951,586 &, 013 \\
\hline No reported dysfunctions & 704 & 1,8170 &, 751 & & & \\
\hline With academic dysfunctions & 322 & 1,9545 &, 838 & $-2,308$ & 532,990 &, 021 \\
\hline Without academic dysfunctions & 860 & 1,8310 &, 765 & & & \\
\hline With developmental dysfunctions & 236 & 1,8866 &, 786 &,- 477 & 1180 &, 633 \\
\hline Without developmental dysfunctions & 946 & 1,8592 &, 787 & & & \\
\hline With psychological dysfunctions & 44 & 2,2805 & 1,075 & $-2,639$ & 44,723 &, 011 \\
\hline Without psychological dysfunctions & 1138 & 1,8486 &, 770 & & & \\
\hline
\end{tabular}

\section{Parental disciplinary practices}

The results regarding the differences in parental practices between the parents with and without the reported child dysfunction are presented in Table 5. 
Table 5

Disciplinary practices in families with children with any reported problem. Note that the CTSPC scale measured the frequency of practices in the 'past year' (a period of 12 months prior to the moment of research), and 'in lifetime' (by marking the response 'not in the past year, but it happened before').

\begin{tabular}{|c|c|c|c|c|c|c|}
\hline Type of practice & Group & $\mathbf{N}$ & Mean & SD & $t$ & $\mathbf{p}$ \\
\hline \multirow{2}{*}{$\begin{array}{l}\text { Nonviolent practice: } \\
\text { Past year }\end{array}$} & $\begin{array}{l}\text { No } \\
\text { dysfunctions }\end{array}$ & 707 & 20,9052 & 21,204 & $-2,865$ &, $004^{\star}$ \\
\hline & $\begin{array}{l}\text { Any } \\
\text { dysfunctions }\end{array}$ & 479 & 24,5470 & 21,885 & & \\
\hline \multirow{2}{*}{$\begin{array}{l}\text { Nonviolent practice: } \\
\text { Lifetime }\end{array}$} & $\begin{array}{l}\text { No } \\
\text { dysfunctions }\end{array}$ & 707 & 1641 & ,520 & $-4,155$ &, $000 \star *$ \\
\hline & $\begin{array}{l}\text { Any } \\
\text { dysfunctions }\end{array}$ & 479 & ,3361 & 798 & & \\
\hline \multirow[t]{2}{*}{$\begin{array}{l}\text { Psychological aggression toward } \\
\text { child: Past year }\end{array}$} & $\begin{array}{l}\text { No } \\
\text { dysfunctions }\end{array}$ & 707 & 10,4130 & 15,194 & $-5,354$ &, $000 * *$ \\
\hline & $\begin{array}{l}\text { Any } \\
\text { dysfunctions }\end{array}$ & 479 & 15,9937 & 19,077 & & \\
\hline \multirow[t]{2}{*}{$\begin{array}{l}\text { Psychological aggression toward } \\
\text { child: Lifetime }\end{array}$} & $\begin{array}{l}\text { No } \\
\text { dysfunctions }\end{array}$ & 707 & ,1132 & 407 & $-3,717$ &, $000 * *$ \\
\hline & $\begin{array}{l}\text { Any } \\
\text { dysfunctions }\end{array}$ & 479 & 2401 & 668 & & \\
\hline \multirow[t]{2}{*}{$\begin{array}{l}\text { Physical assault toward child - } \\
\text { Any type: Past year }\end{array}$} & $\begin{array}{l}\text { No } \\
\text { dysfunctions }\end{array}$ & 707 & 3,3409 & 9,63166 & -641 &, 521 \\
\hline & $\begin{array}{l}\text { Any } \\
\text { dysfunctions }\end{array}$ & 479 & 4,2505 & 9,23020 & & \\
\hline \multirow[t]{2}{*}{$\begin{array}{l}\text { Physical assault toward child- } \\
\text { Any type: Lifetime }\end{array}$} & $\begin{array}{l}\text { No } \\
\text { dysfunctions }\end{array}$ & 707 & 2687 & ,850 & $-5,005$ &, $000 \star \star$ \\
\hline & $\begin{array}{l}\text { Any } \\
\text { dysfunctions }\end{array}$ & 479 & 6284 & 1,408 & & \\
\hline \multirow[t]{2}{*}{$\begin{array}{l}\text { Physical assault toward child - } \\
\text { Minor: Lifetime }\end{array}$} & $\begin{array}{l}\text { No } \\
\text { dysfunctions }\end{array}$ & 707 & 2419 & ,703 & $-5,183$ &, $000 * *$ \\
\hline & $\begin{array}{l}\text { Any } \\
\text { dysfunctions }\end{array}$ & 479 & ,5574 & 1,199 & & \\
\hline \multirow[t]{2}{*}{$\begin{array}{l}\text { Physical assault toward child - } \\
\text { Severe: Lifetime }\end{array}$} & $\begin{array}{l}\text { No } \\
\text { dysfunctions }\end{array}$ & 707 & 0141 & 159 & $-2,883$ &, $004^{\star}$ \\
\hline & $\begin{array}{l}\text { Any } \\
\text { dysfunctions }\end{array}$ & 479 & ,0522 & 257 & & \\
\hline $\begin{array}{l}\text { Physical assault toward child - } \\
\text { Extreme: Lifetime }\end{array}$ & $\begin{array}{l}\text { No } \\
\text { dysfunctions }\end{array}$ & 707 & ,0127 & 180 &,- 533 &, 594 \\
\hline
\end{tabular}




\begin{tabular}{|lllllll|}
\hline Type of practice & Group & N & Mean & SD & t & P \\
\hline Child neglect - Past year & $\begin{array}{l}\text { Any } \\
\text { dysfunctions }\end{array}$ & 479 &, 0188 &, 208 & & \\
\hline Child neglect - Lifetime & $\begin{array}{l}\text { No } \\
\text { dysfunctions }\end{array}$ & 707 & 1,4088 & 4,240 & $-4,753$ &, $000^{\star *}$ \\
\hline $\begin{array}{l}\text { Any } \\
\text { dysfunctions }\end{array}$ & 479 & 3,0585 & 6,747 & & \\
\hline $\begin{array}{l}\text { No } \\
\text { dysfunctions }\end{array}$ & 707 &, 0495 &, 247 & $-3,732$ &, $000^{\star *}$ \\
\hline $\begin{array}{l}\text { Any } \\
\text { dysfunctions }\end{array}$ & 479 &, 1315 &, 435 & & \\
\hline
\end{tabular}

Parents with a reported child dysfunction engaged more in various types of practices comparing to parents without such reports (Table 5). They were significantly more engaged in nonviolent practices as well as in psychological aggression, both in the past year, and during lifetime. When it comes to physical aggression, these parents were also engaged in physical assault in general during lifetime, and more precisely, in minor and severe physical assault, whereas there were no differences in the use of extreme physical assault during lifetime. However, physical assault in general was not differently used in the past year by parents with and without the reports of child dysfunction. This is why the further comparison of three different types of physical aggression (minor, severe and extreme) in the past year was not performed.

\section{Parental practices and positive expectations of CP as predictors of reported child dysfunctions}

The next step was to investigate whether the parental disciplinary practices, parental attitudes towards $\mathrm{CP}$ and expectations of positive $\mathrm{CP}$ outcomes have predictive effects on different types of the reported child dysfunctions.

The multiple linear regression analysis revealed the significant predictors for each type of reported dysfunction in children (Figure 1). The positive bars represent the positive regression coefficients ( $\beta$ coefficient), meaning that higher bar value for each predictor is associated with the higher number of the reported child dysfunctions in the analyzed category. In Figure 1 we presented only significant predictors for each category.

The first regression model showed that $4.2 \%$ of severity of developmental dysfunctions variance in children can be statistically significantly predicted by this model $\left(F(19 ; 1156)=2,676^{* *}\right)$. The significant predictors for this type of difficulty were the expectations positive outcomes of $\mathrm{CP}\left(\beta=.111^{\star}\right)$ and severe physical assault $\left(\beta=.098^{*}\right)$. 
The second multiple linear regression model showed significant prediction of psychological-emotional dysfunctions severity in children with $6.3 \%$ of variance explained by the model $(F(19 ; 1156)=4.120)$. The significant predictors for these types of dysfunctions were all types of physical assault (minor $\left(\beta=.1^{\star}\right)$, severe $\left(\beta=.089^{\star}\right)$, extreme $\left.\left(\beta=.064^{\star}\right)\right)$.

The third multiple linear regression model showed that $13.1 \%$ of variance of academic dysfunctions severity can be significantly predicted by this model $(F(19 ; 1156)=9.19)$. The significant predictors were the psychological aggression towards the child $\left(\beta=.141^{\star \star}\right)$, minor physical assault $\left(\beta=.123^{\star \star}\right)$, and child neglect $\left(\beta=.176^{\star \star}\right)$.

\section{Discussion}

In the present study, we found significant associations of the parental attitudes towards $\mathrm{CP}$, parental expected outcomes of $\mathrm{CP}$, and parental disciplinary practices, with the academic, developmental and psychological child dysfunctions reported by parents.

The most common reported child dysfunction among the participants was the academic dysfunction, reported in every fourth parent $(27.2 \%)$. To our knowledge, there are no studies that report the prevalence of academic dysfunctions of children based on the parental report. Owing to the fact that there was no analogue data in the current literature, the direct comparison of the results was not possible. However, other studies in this area that researched the behavioral dysfunctions in school-aged children report that the prevalence of behavioral difficulties in school-aged children range roughly from $23.5 \%$ in preschool children ${ }^{28}, 36.4 \%$ in children in elementary school ${ }^{29}$.

The second highest reported problem in children in our sample was developmental dysfunction which was reported by every fifth parent (20\%). The reported data from the studies conducted in other countries, that based the prevalence of developmental dysfunctions on a parental report, range from $11.36 \%$ in Taiwan ${ }^{30}$ to $18 \%$ in the United States ${ }^{13}$. A review done in 2007 in low- and middle-income countries reports child disability prevalence from $0.4-12.7 \%$ depending on the study and assessment tool ${ }^{31}$. However, the authors state that the rates can be higher due to the problems in identifying the disabilities and the lack of adequate instruments. The most prevalent developmental dysfunctions in our study were the problems with vision, followed by speech problems and motoric problems. Similar results were found in a recent study done by Chen et al ${ }^{30}$.

The percentage of parents that reported that their child has psychological-emotional dysfunctions was the lowest (3.9\%). In our country, the psychological-emotional dysfunctions among children and adolescents are largely unrecognized and stigmatized. This is especially the case in rural areas ${ }^{32}$. This lack of knowledge with high rates of stigma is probably due to the lack of experts, services, education and systemic support in the field of Child and adolescent psychiatry ${ }^{32}$. This can also be the possible explanation for a high percentage of reported academic dysfunctions, and in contrast, a low percentage of reported psychological-emotional dysfunctions. The occurrence of NSSI reported by parents in our 
study was $1.5 \%$ of parents, while suicidal attempts were reported in $0.4 \%$. This finding is in concordance with the Bella study performed by Resch et al. that reported the prevalence rates of $1.4 \%$ for selfmutilation and/or suicidal attempts, also reported by parents ${ }^{33}$. However, the data in the literature is mainly based on the child reports, and those studies report higher rates of suicidal behavior ${ }^{34,35}$, and higher rates of suicide attempts in youth with a lifetime prevalence of $6 \%{ }^{36}$.

In the present study, our results indicate that parents of children with any reported dysfunction, as well as with any dysfunction separately (developmental, psychological-emotional and academic), more often believe that the outcomes of $\mathrm{CP}$ on children are positive in comparison with the parents of children without reported dysfunctions. In other words, former parents believe that CP will benefit their child's personality and behavior and lead to a behavioral correction, better family relations and learning selfcontrol ${ }^{18}$. One of the first studies that assessed the perceived parental outcomes of CP was done in 2003 by Durrant et al. This study reported that the two samples of mothers in two countries (Sweden and Canada) expected that the outcomes of CP are mainly negative (increased child aggression, long-term emotional upset and parental guilt). A similar finding was also shown among professionals that work with children, where the professionals also believed that the outcomes of CP were primarily negative ${ }^{18}$. This is in line with the findings performed in our country ${ }^{17}$ where we analyzed the differences between the expected outcomes of mothers and fathers ${ }^{17}$.

These studies didn't include the perceptions of parents that care for the child with certain dysfunctions. To our knowledge, there is no previous literature on expected outcomes of parents of a child with a dysfunction. From the qualitative study done by Whittingham et al. ${ }^{37}$ the responses of parents outlined some possible factors that shape their opinions on this matter. Some of these factors included difficulties to determine which behaviors are out of the child's control versus which are amenable to change ${ }^{37}$. Parents that have children with dysfunctions can have a problem in applying alternative and non-violent discipline since these children can have a problem in understanding them, communicating, or hearing them ${ }^{38}$. Moreover, an increased pressure of caring for a child with dysfunctions, additional parenting tasks and behavior management difficulties can, in turn, lead to the increase of parental stress, and the likelihood of believing that CP will be an efficient short- or long-term disciplining method ${ }^{39}$.

Our results also indicate that the attitudes of parents of children with reported dysfunctions towards the use of $\mathrm{CP}$ are positive. When we analyzed each group of dysfunctions we have found that parents of children with psychological and academic dysfunctions have positive attitudes towards $\mathrm{CP}$, while the attitudes of parents of children with developmental dysfunctions don't differ from the attitudes of parents with children without dysfunctions. In a recent study in Taiwan ${ }^{7}$, it has been shown that isolated parental attitudes don't predict the negative outcomes in children. However, when the positive attitudes are combined with the actual use of CP significantly predicts later dysfunctions in children such as depression and violent behavior ${ }^{7}$. 
This leads us to the final aspects of the parental discipline that we analyzed which are the actual parental practices. From the results presented in our study, it can be concluded that the children with any reported problem are significantly more often subjected to all forms of discipline. This is not a surprising result, since the children with difficulties usually require more parental attention, support and guidance in order to achieve their full potential. However, it should be noted that the children with dysfunctions are not only disciplined more by nonviolent practices, but they are also more often exposed to almost all types of violent parental practices. In the past, the researchers constantly report that children with disabilities and behavioral disturbances are constantly more frequently exposed to all forms of violence (physical, emotional) and neglect ${ }^{40-45}$.

When analyzing parental expectations of $\mathrm{CP}$ outcomes, parental attitudes and parental practices as predictors of the reported child dysfunctions among the participants, we found significant effects. The significant predictors for the reported developmental dysfunctions in children were the parental positive expectations of CP (i.e. positive outcomes) as well as the parental use of physical assault. In the past, researchers have reported that children with certain developmental difficulties are constantly more often exposed to abuse. According to the authors, this is mainly due to their common cognitive immaturity and social invisibility ${ }^{46}$. There is an increasing body of evidence that abuse (especially severe forms of abuse) alters brain development ${ }^{43}$. It needs to be highlighted that these children are already more vulnerable to all types of adverse external factors, and even with sufficient support often struggle to reach their full potential and to adequately follow their peers. We can conclude that the effects of abuse in this group of children can be even more devastating in terms of their further development.

The significant predictors of academic dysfunctions in children were psychological aggression, minor physical assault and neglect. The significant predictors for psychological-emotional dysfunctions in children were all forms of physical abuse (minor to extreme). Considering the fact that this is a crosssectional study, the associations between the examined variables can be bidirectional. The use of CP and other harsh disciplining measures can lead to many negative mental health outcomes for a child such as internalizing (depression, NSSI, suicidal behavior) ${ }^{47,48}$ and externalizing problems (increased impulsivity, temper outbursts, and aggression) ${ }^{49}$. This is why parents need to bear in mind the fact that not only these violent measures are not going to resolve the child's dysfunctions, but they can cause and/or worsen them. On the other hand, the challenging behaviors that are often expressed by children with dysfunctions can lead to a decrease in parental capacity to handle their demanding parental role and to deal with stress, which can worsen their unfavorable discipline practices. These factors can form a virtuous circle that can be dangerous for the whole family.

The main limitation of this study is its cross-sectional structure and its inability to form a causal relationship between the measured variables. The use of self-report and the retrospective nature of some parts of the study instrument may have caused a recall bias among the participants. In addition, this study was based on parental reports of child dysfunctions, which could have led to false negative and false positive identification of certain dysfunctions in their children. The participants were approached by 
the interviewer in their household and the interview was conducted face-to-face. Some questions could have been sensitive and possibly incriminating for certain parents, which is why they might have been reluctant to provide truthful answers.

\section{Conclusion}

On the basis of the findings from this research, we have evidence that parents of children with certain dysfunctions have positive attitudes towards violent punishment, as well as the positive expectation of CP. In addition, the children with dysfunctions are more often subjected to CP and other forms of violent disciplining. When these three measured effects combine, this puts the children with health-related and school-related issues at a significant risk of further maltreatment and abuse. More studies are needed to assess the exact additive effects and interaction between these factors, as well as causal relationships between the factors related to children and parental opinions and practices.

This study highlights the need for close cooperation between the researchers and policymakers that need to provide comprehensive systems of support and education which can help in the prevention of child maltreatment. As seen from this study, these systems need to be especially directed towards parents and families that care for a child with dysfunctions due to their increased vulnerability. Owing to the fact that parental opinions and attitudes are a large piece of the puzzle related to parental practices, the education of parents on "positive parenting" and adequate disciplining measures should be at the forefront of preventive interventions.

\section{Declarations}

\section{Acknowledgements}

None.

\section{Author contributions statement}

R.G., O.T. and M.P.M. designed the study, performed the literature search and wrote the manuscript. O.T. performed the statistical analysis. R.G., A.R., O.T. were involved in the recruitment of the participants. L.L., M.V., A.R., O.T and R.G. were included in the process of interviewing, and data collection. M.M.V., V.M.M., T.P., M.P.M., L.L., M.V. and J.R.K. supervised the research, reviewed the manuscript and gave critical comments to the manuscript. All of the authors reviewed and approved the final version of the manuscript.

\section{Additional Information (including a Competing Interests Statement)}

This research was supported and financed by UNICEF Serbia. The following researchers received financial compensation as being part of the research group: Dr. Roberto Grujicic, Prof. Oliver Toskovic, Ljiljana Lazarevic, Dr. Vanja Mandic Maravic, Dr. Marija Mitkovic Voncina, Ana Radanovic, Prof. Jelena 
Radosavljev Kircanski, Marina Videnovic and Prof. Milica Pejovic Milovancevic. Prof. Tatjana Pekmezovic declares no potential conflict of interest.

\section{Availability of Data and Materials}

The database generated during this study is included in this published article under supplementary material.

\section{References}

1. Corporal Punishment of Children in Theoretical Perspective. (Yale University Press, 2005).

2. Durrant, J. \& Ensom, R. Physical punishment of children: lessons from 20 years of research. CMAJ 184, 1373-1377 (2012).

3. Cuartas, J. \& Herbert, B. Ending corporal punishment in the early years of childhood: an essential right and need of every young child. 18 https://www.end-violence.org/ (2021).

4. Altschul, I., Lee, S. J. \& Gershoff, E. T. Hugs, Not Hits: Warmth and Spanking as Predictors of Child Social Competence. J. Marriage Fam. 78, 695-714 (2016).

5. United Nations Children's Fund: Hidden in Plain Sight: A statistical analysis of violence against children. UNICEF (2014) doi:10.1053/j.gastro.2019.02.033.

6. Gershoff, E. T. \& Grogan-Kaylor, A. Spanking and child outcomes: Old controversies and new metaanalyses. J. Fam. Psychol. JFP J. Div. Fam. Psychol. Am. Psychol. Assoc. (Division 43) 30, 453-469 (2016).

7. Chen, J.-K., Pan, Z. \& Wang, L.-C. Parental Beliefs and Actual Use of Corporal Punishment, School Violence and Bullying, and Depression in Early Adolescence. International Journal of Environmental Research and Public Health vol. 18 (2021).

8. Stalker, K. \& McArthur, K. Child abuse, child protection and disabled children: a review of recent research. Child Abus. Rev. 21, 24-40 (2012).

9. Hendricks, C., Lansford, J. E., Deater-Deckard, K. \& Bornstein, M. H. Associations between child disabilities and caregiver discipline and violence in low- and middle-income countries. Child Dev. 85, 513-531 (2014).

10. Alizadeh, H., Applequist, K. F. \& Coolidge, F. L. Parental self-confidence, parenting styles, and corporal punishment in families of ADHD children in Iran. Child Abuse Negl. 31, 567-572 (2007).

11. Reid, J., Patterson, G. \& Snyder, J. Antisocial Behavior in Children and Adolescents: A Developmental Analysis and Model for Intervention. Am. J. Psychiatry - AMER J PSYCHIAT 160, (2002).

12. Van Horne, B. S. et al. Maltreatment of Children Under Age 2 With Specific Birth Defects: A Population-Based Study. Pediatrics 136, e1504-12 (2015).

13. Zablotsky, B. et al. Prevalence and Trends of Developmental Disabilities among Children in the United States: 2009-2017. Pediatrics 144, (2019). 
14. Mazur, E. \& Mickle, C. L. Online Discourse of the Stressors of Parenting Children with Mental Health Disorders. J. Child Fam. Stud. 27, 569-579 (2018).

15. Theule, J., Wiener, J., Tannock, R. \& Jenkins, J. M. Parenting Stress in Families of Children With ADHD: A Meta-Analysis. J. Emot. Behav. Disord. 21, 3-17 (2010).

16. Roetzel, A. C. Physical punishment across generations: Factors associated with continuity and change in subsequent generations. in (2008).

17. Grujicic, R. et al. Research on child disciplining at home in Serbia. (2020).

18. Taylor, C. A., Fleckman, J. M. \& Lee, S. J. Attitudes, beliefs, and perceived norms about corporal punishment and related training needs among members of the 'American Professional Society on the Abuse of Children'. Child Abuse Negl. 71, 56-68 (2017).

19. Fass, M. \& Khoury-Kassabri, M. Associations between Arab Mothers' Self-Efficacy and Parenting Attitudes and their children's Externalizing and Internalizing Behaviors: Gender Differences and the Mediating Role of Corporal Punishment. Child Indic. Res. 11, (2018).

20. Barnett, M. A., Shanahan, L., Deng, M., Haskett, M. E. \& Cox, M. J. Independent and Interactive Contributions of Parenting Behaviors and Beliefs in the Prediction of Early Childhood Behavior Problems. Parent. Sci. Pract. 10, 43-59 (2010).

21. Durrant, J., Rose-Krasnor, L. \& Broberg, A. Physical Punishment and Maternal Beliefs in Sweden and Canada. J. Comp. Fam. Stud. 34, 585-604+ii (2003).

22. Korbin, J. E. Cross-cultural perspectives and research directions for the 21st century. Child Abuse Negl. 15 Suppl 1, 67-77 (1991).

23. Gagné, M.-H., Tourigny, M., Joly, J. \& Pouliot-Lapointe, J. Predictors of adult attitudes toward corporal punishment of children. J. Interpers. Violence 22, 1285-1304 (2007).

24. Straus, M. A. \& Hamby, S. L. Measuring physical and psychological maltreatment of children with the Conflict Tactics Scales. Out of darkness: Contemporary perspectives on family violence. 119-135 (1997) doi:10.4135/9781483328058.n10.

25. Straus, M. A., Hamby, S. L., Finkelhor, D., Moore, D. W. \& Runyan, D. Identification of child maltreatment with the Parent-Child Conflict Tactics Scales: development and psychometric data for a national sample of American parents. Child Abuse Negl. 22, 249-270 (1998).

26. Cotter, A., Proctor, K. B. \& Brestan-Knight, E. Assessing child physical abuse: An examination of the factor structure and validity of the Parent-Child Conflict Tactics Scale (CTSPC). Child. Youth Serv. Rev. 88, 467-475 (2018).

27. GRAZIANO, A. M., LINDQUIST, C. M., KUNCE, L. J. \& MUNJAL, K. Physical Punishment in Childhood and Current Attitudes: An Exploratory Comparison of College Students in the United States and India. J. Interpers. Violence 7, 147-155 (1992).

28. Santos, L. M. Dos, Queirós, F. C., Barreto, M. L. \& Santos, D. N. Dos. Prevalence of behavior problems and associated factors in preschool children from the city of Salvador, state of Bahia, Brazil. Rev. Bras. Psiquiatr. 38, 46-52 (2016). 
29. Abdolahzadeh, Z., Bigdeli, I. \& Mashhadi, A. The Prevalence of Behavioral Problems Among Primary School Children in Outskirts of Mashhad City, Iran. Iran. J. Psychiatry Behav. Sci. 12, (2018).

30. Chen, H.-J., Hsin-Ju Ko, M., Li, S.-T., Chiu, N.-C. \& Hung, K.-L. Prevalence of preschool children developmental disabilities in northeastern Taiwan - Screening with Taipei City Developmental Screening Checklist for Preschoolers, 2nd Version. J. Formos. Med. Assoc. 119, 1174-1179 (2020).

31. Maulik, P. K. \& Darmstadt, G. L. Childhood disability in low- and middle-income countries: overview of screening, prevention, services, legislation, and epidemiology. Pediatrics 120 Suppl, S1-55 (2007).

32. Pejovic-Milovancevic, M., Grujicic, R., Stupar, S. \& Ninkovic, M. Overcoming traps and challenges in child and adolescent psychiatry. Srp. Arh. Celok. Lek. 149, 236-241 (2021).

33. Resch, F., Parzer, P. \& Brunner, R. Self-mutilation and suicidal behaviour in children and adolescents: prevalence and psychosocial correlates: results of the BELLA study. Eur. Child Adolesc. Psychiatry 17 Suppl 1, 92-98 (2008).

34. Cipriano, A., Cella, S. \& Cotrufo, P. Nonsuicidal Self-injury: A Systematic Review. Front. Psychol. 8, 1946 (2017).

35. Swannell, S. V, Martin, G. E., Page, A., Hasking, P. \& St John, N. J. Prevalence of nonsuicidal self-injury in nonclinical samples: systematic review, meta-analysis and meta-regression. Suicide Life. Threat. Behav. 44, 273-303 (2014).

36. Lim, K.-S. et al. Global Lifetime and 12-Month Prevalence of Suicidal Behavior, Deliberate Self-Harm and Non-Suicidal Self-Injury in Children and Adolescents between 1989 and 2018: A Meta-Analysis. Int. J. Environ. Res. Public Health 16, (2019).

37. Whittingham, K., Wee, D., Sanders, M. \& Boyd, R. Responding to the challenges of parenting a child with cerebral palsy: a focus group. Disabil. Rehabil. 33, 1557-1567 (2011).

38. Knutson, J. F., Johnson, C. R. \& Sullivan, P. M. Disciplinary choices of mothers of deaf children and mothers of normally hearing children. Child Abuse Negl. 28, 925-937 (2004).

39. Weisleder, P. Family interventions to prevent maltreatment of children with disabilities. J. Child Neurol. 26, 1052-1053 (2011).

40. Hutt, J. M. Child maltreatment. Forensic Leg. Dent. 159-164 (2014) doi:10.1007/978-3-319-013305_16.

41. Sullivan, P. M. \& Knutson, J. F. Maltreatment and disabilities: a population-based epidemiological study. Child Abuse Negl. 24, 1257-1273 (2000).

42. Chu, A., Pineda, A., Deprince, A. \& Freyd, J. Vulnerability and protective factors for child abuse and maltreatment. Violence against Women Child. Vol 1 Mapp. Terrain 1, 55-75 (2011).

43. Sullivan, P. M. Children with Disabilities Exposed to Violence: Legal and Public Policy Issues. in Children exposed to violence. 213-237 (Paul H. Brookes Publishing Co., 2006).

44. Leeb, R. T., Bitsko, R. H., Merrick, M. T. \& Armour, B. S. Does Childhood Disability Increase Risk for Child Abuse and Neglect? J. Ment. Health Res. Intellect. Disabil. 5, 4-31 (2012). 
45. Maclean, M. et al. Abuse and neglect in children with disabilities: risk varies by type of disability. Int. J. Popul. Data Sci. 1, (2017).

46. Organization, W. H. Preventing child maltreatment: a guide to taking action and generating evidence / World Health Organization and International Society for Prevention of Child Abuse and Neglect.

47. Afifi, T. O. et al. Spanking and adult mental health impairment: The case for the designation of spanking as an adverse childhood experience. Child Abuse Negl. 71, 24-31 (2017).

48. Liu, J., Liu, X., Wang, H. \& Gao, Y. Harsh parenting and non-suicidal self-injury in adolescence: the mediating effect of depressive symptoms and the moderating effect of the COMT Val158Met polymorphism. Child Adolesc. Psychiatry Ment. Health 15, 70 (2021).

49. Morris, S. Z. \& Gibson, C. L. The Causal Effect of Corporal Punishment on Children's Internalizing and Externalizing Behavioral Outcomes: Results from a Propensity Score Matching Analysis. (Georgia Southern University, 2007).

\section{Figures}

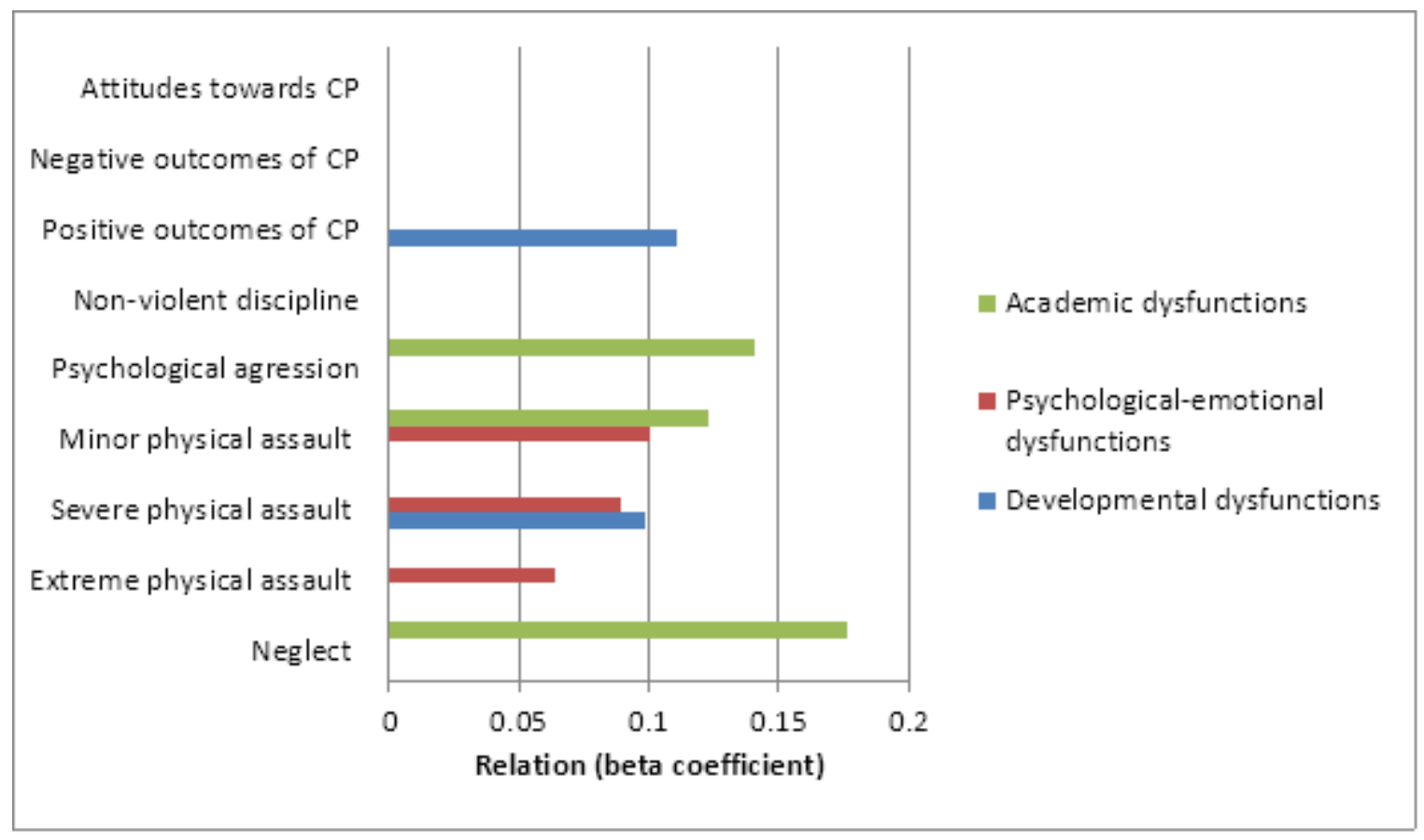

\section{Figure 1}

Summary of the relationships between the expected outcomes of $\mathrm{CP}$, attitudes towards $\mathrm{CP}$ and disciplinary practices and the different types of children's difficulties expressed via beta (regression) coefficient. Note that only significant findings were shown in the figure.

\section{Supplementary Files}

This is a list of supplementary files associated with this preprint. Click to download. 
- Data.xlsx

Page 21/21 